\title{
Title: SUPERVISORS' EXPERIENCE OF
}

\author{
DELIVERING INDIVIDUAL CLINICAL
}

\section{SUPERVISION TO QUALIFIED THERAPISTS: A}

\section{META-ETHNOGRAPHIC SYNTHESIS}

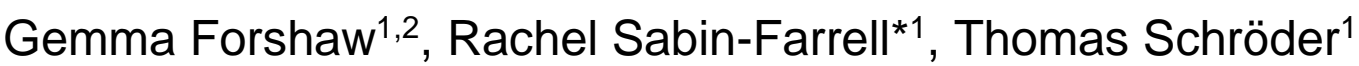

${ }^{1}$ Division of Psychiatry and Applied Psychology, University of

Nottingham, UK

${ }^{2}$ Derbyshire Healthcare NHS Foundation Trust, Derbyshire, UK

* Corresponding author information: Rachel Sabin-Farrell, Division of Psychiatry \& Applied Psychology, The University of Nottingham, YANG Fuija Building, Wollaton Road, Nottingham. NG8 1BB. UK. (e-mail: rachel.sabin-farrell@nottingham.ac.uk). 
Supervisors' experience of delivering individual clinical supervision to qualified therapists: $A$ meta-ethnographic synthesis

\section{Abstract}

Purpose: This review systematically identifies, appraises, and synthesises qualitative literature exploring the experience, both positive and negative, of clinical supervision from the supervisor's perspective.

Design/Methodology/Approach: A systematic search of three databases, grey literature, reference lists, and citations was conducted. Six articles met the inclusion criteria and their quality was critically appraised by using a modified version of the Critical Appraisal Skills Programme tool. Data extracted from the articles were synthesised using meta-ethnography.

Findings: Four key themes were identified: experiencing difficulties in clinical supervision, responsibility, similarities to therapy, and capabilities as a supervisor. These demonstrated that the role of a supervisor has the potential to be both beneficial and harmful to personal and professional development.

Research Limitations/Implications: The quality of the studies was variable. Further research is required to explore how supervisors manage difficult experiences to ensure personal development and growth.

Practical Implications: Clinical implications include the need for employers to consider the additional pressure associated with providing clinical supervision and to ensure that appropriate support is available. Results complement previous research on the bi-directionality of parallel process in clinical supervision.

Originality/Value: This review presents an original synthesis of the supervisor's experience of delivering clinical supervision to qualified therapists. This is achieved by utilising a systematic methodology and appraising the quality of the studies included. The review highlights how the effects of clinical supervision are not limited to the supervisee, but also experienced by the supervisor. The competing demands 
Supervisors' experience of delivering individual clinical supervision to qualified therapists: $A$ meta-ethnographic synthesis

and responsibilities associated with clinical supervision impact upon the supervisor's experience, both positively and negatively. When beneficial, delivering clinical supervision can lead to personal and professional growth in addition to the acquisition of new skills.

\section{Introduction}

The Division of Clinical Psychology (DCP; British Psychological Society [BPS], 2014) defines supervision's primary purpose as safeguarding the service-user, ensuring they receive quality treatment and care. Secondary objectives include: professional development, acquiring additional skills, facilitating reflection, and individual support. Elaborating upon the primary objective, supervision serves to ensure supervisees are adhering to good practice and receive assistance for their formulation, reformulation, and delivery of intervention. Whilst frequently confused with managerial supervision, clinical supervision does not involve a managerial agenda (Adams, Holman, \& Mitchell, 2003). Clinical supervision is defined as "the formal provision by senior/qualified health practitioners (or similarly experienced staff) of an intensive, relationship-based, education and training that is case-focused and which supports, directs and guides the work of colleagues (supervisees)" (Milne, 2007, p. 440). For this review, the term supervision will refer to clinical supervision.

Supervision can occur both individually and in group settings. Group supervision has the advantage of generating richer sources of feedback, reflections, and contributions, provided by multiple clinicians, reducing dependency or overinfluence of a supervisor (Hawkins \& Shohet, 2006). However, providing supervision in a group format may hamper a supervisor's ability to deliver best practice as group processes can be detrimental to supervisory processes: feelings of shame may be 
Supervisors' experience of delivering individual clinical supervision to qualified therapists: $A$ meta-ethnographic synthesis

exacerbated when revealing shortcomings, and rivalry may occur when discussing successes (Borders, 2014; Gautier, 2009; Hawkins \& Shohet, 2006). Hence, individual supervision has been found to facilitate deeper reflection and learning (Ögren, Boëthius, \& Sundin, 2014).

There are documented discrepancies between different disciplines in using supervision; e.g., practice guidelines regarding format, duration, and frequency (British Association for Counselling and Psychotherapy, 2010; BPS, 2014; Inman et al., 2014).

The effects of supervision extend beyond supervisees to their clients; beneficial effects for clients include symptom reduction and increased ethical practice of their therapist (Bradshaw, Butterworth, \& Mairs, 2007; Lichtenberg, 2007; Watkins, 2011). Supervision has been found to promote skill development and enable therapists to explore their emotional responses to clients, increasing their ability to effectively manage therapeutic processes without distraction (Ögren \& Jonsson, 2004; Vallance, 2005).

Negative experiences of supervision have been found to contribute towards poor therapist-client relationships, an alliance shown to highly correlate with client outcome (Lambert \& Barley, 2001; Ramos-Sánchez et al., 2002). Much of the literature has received criticism for lack of follow-up and methodological flaws (Freitas, 2002; Watkins, 2011). Nonetheless, it highlights the potential sequalae of difficulties in supervision towards clients.

The theory of parallel process provides one explanation of the importance of supervision for client well-being. It is based on the psychodynamic concept of transference, where the dynamics of one relationship are unconsciously mirrored into a different relationship (Bernard \& Goodyear, 2009). Thus, the supervisee-client 
Supervisors' experience of delivering individual clinical supervision to qualified therapists: $A$ meta-ethnographic synthesis

relationship in therapy is reflected within supervision (Jacobsen, 2007), in turn affecting both supervisee's and supervisor's experience of process. To prevent supervisory and consequent therapeutic ruptures, it is critical that supervisors identify such incidents (Koltz, Odegard, Feit, Provost, \& Smith, 2012; Rubinstein, 1993). Parallel process can occur bi-directionally, bottom-up (client-therapistsupervisor) and top-down (supervisor-therapist-client), and the point of origin can occur with any participant within the supervisory triad (Ekstein \& Wallerstein, 1958; Searles, 1955). Whilst the notion of parallel process originates from psychodynamic theory (Morrissey \& Tribe, 2001), the phenomenon has been identified within other orientations (Raichelson, Herron, Primavera, \& Ramirez, 1997) and has been described as supervision's most influential concept (Binder \& Strupp, 1997). By understanding parallel process, supervisees can better comprehend their work with clients and parallel treatment-supervision difficulties can be explored and addressed (Carroll 1996; Watkins, 2017). As this phenomenon is not limited to supervisees, supervisor's experiences are also of interest.

The current literature predominantly relates to trainees; however, supervision is governed by the supervisee's career stage (Wheeler \& Richards, 2007). Trainee therapists must act as clinical subordinates; however, the consequent power imbalances can be damaging to the supervisory relationship (Kilminster \& Jolly, 2000; Nelson \& Friedlander, 2001; Worthington, 1987). In addition, supervisors contribute to decisions about trainees' progression on their training courses (BPS, 2007). Once such dominant evaluative roles are absent, power imbalances should reduce (Aryee, Sun, Chen, \& Debrah, 2008). Thus, the current literature exploring supervision cannot be generalised to qualified staff (Green \& Youngson, 2003). 
Supervisors' experience of delivering individual clinical supervision to qualified therapists: $A$ meta-ethnographic synthesis

To summarise supervisors have multiple tasks within supervision, requiring them to adopt an array of roles which can be influenced by numerous factors: firstly, whether their supervisee is qualified or in training, in the latter case the supervisor's role incorporates being an evaluator (BPS, 2007). Secondly, supervisors are expected to govern and assure the quality of their supervisees' therapy delivery (Fleming \& Steen, 2013). Thirdly, supervisors are required to provide a reflective space for their supervisees, exploring the emotional experience of working therapeutically with clients (Wheeler, 2007). In addition, the supervisor must also manage the dynamics of the supervisory relationship (Pearson, 2000). Furthermore, whilst supervision is for the supervisee's benefit, providing it may have implications for the supervisor (Wheeler, 2007). Yet a minority of research pertaining to supervision considers supervisors' experiences (Nelson \& Friedlander, 2001). Understanding their perspective would generate a greater knowledge of the components required to deliver quality supervision and the potential difficulties or obstacles faced (Trede, McEwen, Kenny, \& O'Meara, 2014).

Much of the research on supervision is quantitative, with the majority exploring supervisee development, client and supervision outcome, and measure development (Wheeler \& Richards, 2007). However, quantitative research fails to capture the voice of the participant, and research questions previously asked precluded the exploration of positive elements, a common occurrence within psychology research (Austin \& Sutton, 2014; Seligman \& Csikszentmihalyi, 2014). Whilst attempts have been made to redress this balance with emerging qualitative research, due to the nature of qualitative methodologies they are frequently limited to small sample sizes and are therefore insufficient to inform practice guidelines in isolation (Miller, 2010). Nevertheless, if qualitative research is situated within a larger context, it could be 
Supervisors' experience of delivering individual clinical supervision to qualified therapists: $A$ meta-ethnographic synthesis

interpreted in unison and facilitate change (Thorne, 2016). In response, the use of meta-analysis of qualitative literature is increasing (Moher et al., 2015). This has amplified the audience of qualitative findings and increased accessibility, enabling greater influence on policy, research, and clinical practice (Finfgeld, 2003). Metasynthesis allows additional exploration of multi-layered phenomena that would not be accessible in standalone texts (Sandelowski, Docherty, \& Emden, 1997). It combines the results from qualitative research on a similar topic to answer a new research question proposed by the synthesist; generating additional knowledge (Zimmer, 2006).

The most frequently utilised and developed methodology of meta-synthesis is meta-ethnography, originating from the interpretative paradigm, which aims to generate an inductive and interpretive knowledge synthesis, and therefore is wellsuited to qualitative research and interpretative epistemologies (Britten et al., 2002; Campbell et al., 2012; Noblit \& Hare, 1988). Meta-ethnography enables cross-case conclusions to be drawn, facilitating a new interpretation of literature (Noblit \& Hare, 1988). It is being increasingly utilised within healthcare research and has the potential to improve service delivery (Atkins et al., 2008).

In an attempt to explore the identified paucity of research into supervision of qualified therapists, this review adopted a critical interpretive approach to combine and integrate the current literature on supervision, in order to generate a higherorder contribution.

This review had two aims: to systematically identify and appraise qualitative papers which investigated both positive and negative experiences of supervision from the supervisor's perspective; and to synthesise the findings of identified studies to provide further understanding of this experience. A synthesis of similarities and 
Supervisors' experience of delivering individual clinical supervision to qualified therapists: $A$ meta-ethnographic synthesis

discrepancies of supervisors' experiences amongst existing literature, would improve the influence of standalone qualitative papers. From elucidating the understandings of current research, richer comprehension of the experience could be generated.

This may develop, or contest, current knowledge and practice, providing direction for future research. Therefore, the review question is: What are the supervisor's experiences of providing clinical supervision to qualified therapists?

\section{Methods}

Meta-ethnography has structured guidelines which have been adopted in this review, see Box 1 (Noblit \& Hare, 1988).

The first author previously identified this topic was important to synthesise (Phase 1). Initial scoping of the literature identified that focused searching produced limited papers, therefore search terms and aims were broadened. The research question was formulated to capture relevant research incorporating both the challenges and positives of supervision.

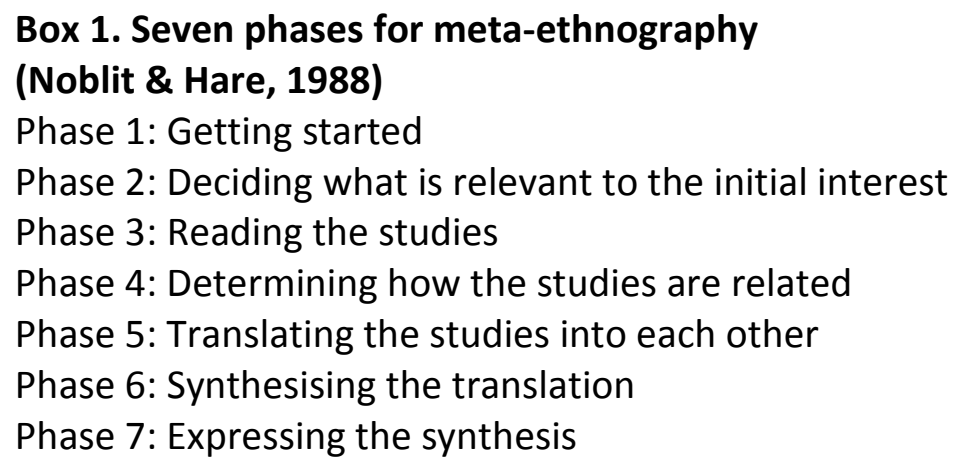

The first author of this review is a trainee clinical psychologist with an interest in supervision. As bias can occur at any point in a study, this was considered before the review commenced (Pannucci \& Wilkins, 2010). The first author compiled a list of anticipated themes, which were bracketed to facilitate openness to the metaethnography (Richards, 2014). 
Supervisors' experience of delivering individual clinical supervision to qualified therapists: $A$ meta-ethnographic synthesis

A reflective journal was utilised during synthesis to assist reflexivity and demonstrate the translation process. Guidance procedures were adhered to, and detailed records were maintained ensuring transparency and replicability of the article identification process. Further implications of researcher bias are outlined in the discussion.

\section{Searching}

A comprehensive systematic literature search was conducted on 01/02/2019 encompassing three electronic databases: Cumulative Index of Nursing and Allied Health Literature (CINAHL), MEDLINE, and PsychINFO. These were selected due to relevance to the field and frequent adoption in similar reviews (for example: Ducat, 2013; Ducat \& Kumar, 2015; Milne et al., 2010). In addition, OpenGrey was utilised to identify unpublished literature to avoid publication bias. The reference list of fulltext articles was hand-searched, and citations reviewed to discover additional literature.

\section{Terms}

Search terms included: supervis*[1] AND therap* AND qualitative AND experience, for a full list please contact the corresponding author. No restriction on year of publication was imposed.

\section{Selection}

The article selection procedure is detailed in the Preferred Reporting Items for Systematic Literature Reviews and Meta-Analysis (PRISMA; Figure 1; Liberati et al.,

${ }^{[1]}$ The suffix * enables truncation of search terms to provide an expansive search of the databases. 
Supervisors' experience of delivering individual clinical supervision to qualified therapists: $A$ meta-ethnographic synthesis

2009). Articles were initially reviewed by title and abstract and later in full-text to determine eligibility against inclusion criteria (Phases 2-3). Papers were included if they met the following criteria:

- Explored supervisors' perspective of supervision.

- Employed qualitative methodology.

- The supervisor was a psychologist, psychotherapist, or counsellor.

Studies were excluded if:

- Supervision included trainees or students.

- Supervision utilised a group format.

- Articles were not published in English.

- Data from supervisors and supervisees could not be separated.

- Articles could not be accessed ${ }^{[2]}$.

\section{Quality Appraisal}

An agreement within qualitative research is yet to be reached regarding what specifications are required to demonstrate quality or validity. This may reflect the variety of epistemological positions whereby such research is undertaken (Garside, 2014). Many promote the use of formal quality appraisal checklists to increase credibility (Campbell et al., 2003; Walsh \& Downe, 2005), advocating their use to limit the risk of unreliable conclusions (Thomas \& Harden, 2008). The quality of the studies included in this review were assessed by the first author and a sub-sample was independently appraised by the second author. This was completed by utilising a modified version of the Critical Appraisal Skills Programme (CASP) tool (CASP,

\footnotetext{
${ }^{22]}$ All attempts were made to gain access, however due to following reasons six articles have not been included: no author contact details; no response from author; paper not digitised.
} 
Supervisors' experience of delivering individual clinical supervision to qualified therapists: A meta-ethnographic synthesis

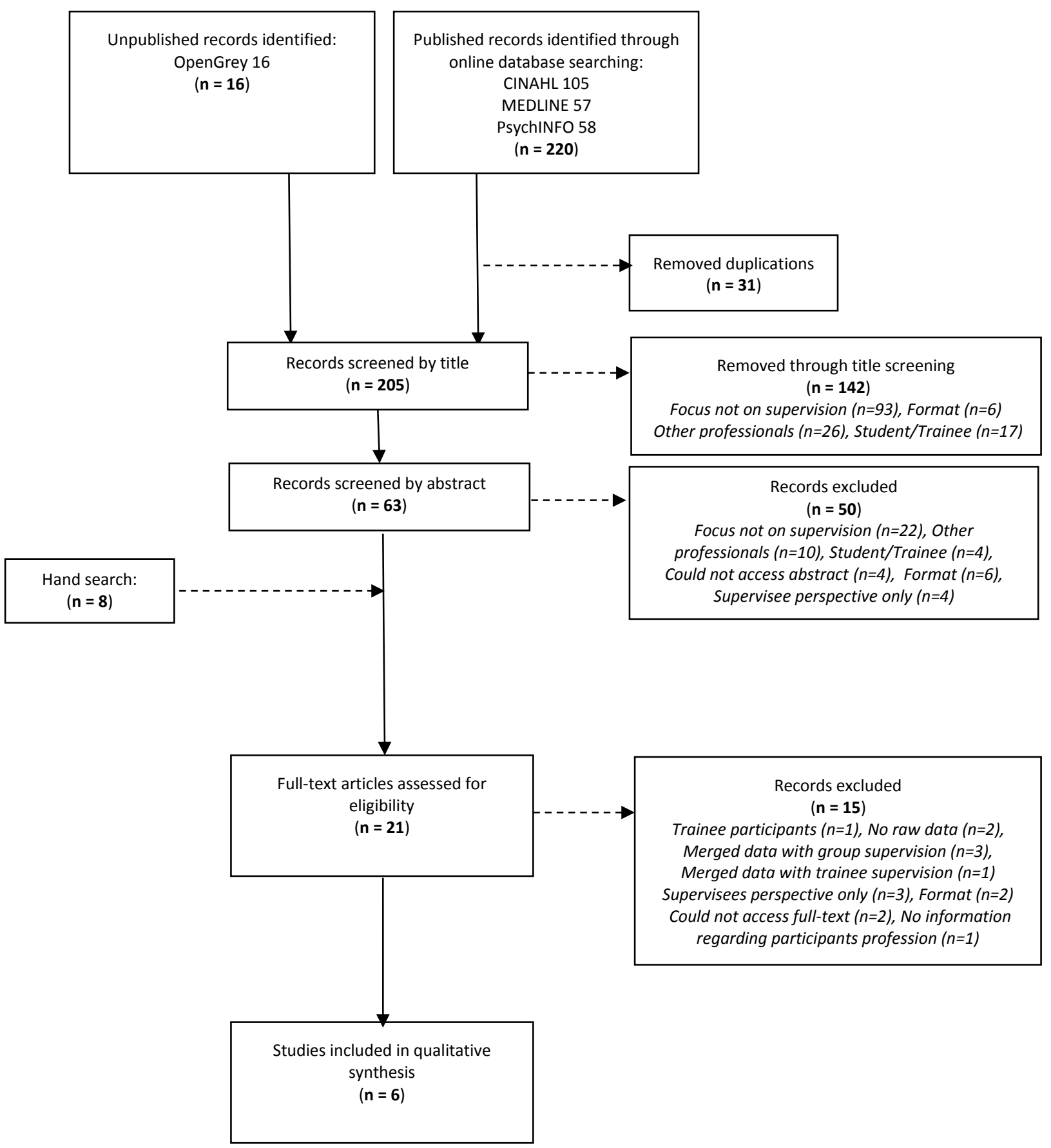

Figure 1. Selection and Exclusion Process of Articles (PRISMA flowchart, Liberati et

al., 2009) 
Supervisors' experience of delivering individual clinical supervision to qualified therapists: A metaethnographic synthesis

2017). For ease of reference, each study was assigned a number which has been referred to throughout the review (see Table 2). In total, sixteen quality criteria were specified, and articles were marked as either zero, not met; one, partially met; two, clearly met.

\section{Data abstraction}

In accordance with Noblit and Hare's (1988) guidelines, the articles were repeatedly read, and their key characteristics extracted, including research findings, interpretations, discussion, and conclusions. Initial assumptions were developed about the relationships between studies (Phase 4). Participant accounts included in the studies represent primary data and are described as first-order constructs, and the analysis and interpretations of such into themes are second-order constructs (Schutz, 1962). To continue to interpret how the studies related to each other, the first author entered third-order constructs into a spreadsheet and completed a crosscomparison to identify similarities across the studies. The three formats of metaethnography synthesis were consecutively applied (Phases 4-6):

(A) Reciprocal translation: Identifying similarities between themes across studies and adopting or adjusting a title to ensure the overarching feature is articulated.

(B) Refutational synthesis: Recognising where themes discuss similar phenomena, but express conflicting views and adopting a title that can encompass the disparity.

(C) Line of argument: The synthesis of (A) and (B) to develop new meaning. 
Supervisors' experience of delivering individual clinical supervision to qualified therapists: A metaethnographic synthesis

\section{Results}

\section{Quality Appraisal}

The results of the quality appraisal varied, with total scores ranging from 16-28 (see Table 1). It is worth noting that the paper deemed to be of the highest quality was a thesis (2) and therefore not subjected to the word restrictions of journals. Despite this, one journal (3) scored a similar score, demonstrating the variability of the quality of papers included.

Every study clearly specified their research aims, which all referred to exploring the supervisor's perspective of supervision. All selected qualitative methodologies which would appear to answer their research question, but only half justified their research design $(1,2,3)$. Whilst each study provided raw data to support their findings, only four provided this sufficiently and accounted for contradictory evidence $(1,2,3,4)$. However, there may have been no contradictory data. Half of the studies failed to specify their epistemological position $(4,5,6)$, which restricts the reader's ability to understand and interpret proposed findings (Paterson \& Canam, 2001). Only one study (5) was explicit in its achievement of data sufficiency, whereby no new novel information was gathered, only confirming existing themes (Suri, 2011).

The debate continues regarding whether the quality of an article should determine exclusion within a review (Atkins et al., 2008). While a study may be poorly reported, this does not mean it has been poorly conducted (Dixon-Woods, Shaw, Agarwal, \& Smith, 2004). Evans and Pearson (2001) argued that though a study may be interpreted as 'poor quality', the information it contains remains valid. Whilst the appraisal identified articles of lower quality, the content within may still be important, therefore no articles were excluded. 
Supervisors' experience of delivering individual clinical supervision to qualified therapists: A metaethnographic synthesis

Table 1.

Assessment of Quality of Selected Studies using CASP criteria

\begin{tabular}{|c|c|c|c|c|c|c|c|}
\hline & & & & dy $N$ & umb & & \\
\hline & & 1 & 2 & 3 & 4 & 5 & 6 \\
\hline & Quality Criteria & & & & & & \\
\hline 1 & Clear statement of research aims & 2 & 2 & 2 & 2 & 2 & 2 \\
\hline 2 & Epistemological position specified & 1 & 2 & 2 & 0 & 0 & 0 \\
\hline 3 & Appropriate qualitative methodology & 2 & 2 & 2 & 2 & 2 & 2 \\
\hline 4 & Appropriate research design & 2 & 2 & 2 & 1 & 1 & 1 \\
\hline 5 & Appropriate recruitment strategy & 1 & 1 & 1 & 1 & 2 & 1 \\
\hline 6 & Data collection explained & 2 & 1 & 2 & 1 & 1 & 2 \\
\hline 7 & Discussion of data sufficiency & 1 & 1 & 1 & 0 & 2 & 0 \\
\hline 8 & $\begin{array}{l}\text { Researcher and participant relationship considered } \\
\text { (e.g. potential influence during data collection etc.) }\end{array}$ & 1 & 2 & 1 & 0 & 1 & 0 \\
\hline 9 & Sufficient ethical considerations & 2 & 2 & 1 & 1 & 0 & 2 \\
\hline 10 & Rigorous data analysis & 2 & 2 & 2 & 1 & 1 & 1 \\
\hline 11 & Clear statement of findings & 2 & 2 & 2 & 2 & 2 & 1 \\
\hline 12 & Sufficient evidence to support identified themes & 2 & 2 & 2 & 2 & 1 & 1 \\
\hline 13 & $\begin{array}{l}\text { Credibility of findings discussed } \\
\text { (e.g. triangulation, multiple analysts) }\end{array}$ & 1 & 1 & 1 & 0 & 2 & 1 \\
\hline 14 & Reflexivity considered & 2 & 2 & 2 & 0 & 2 & 0 \\
\hline 15 & Clear contribution to existing knowledge & 2 & 2 & 2 & 1 & 2 & 1 \\
\hline 16 & Valuable research & 2 & 2 & 2 & 2 & 2 & 2 \\
\hline & Total & 27 & 28 & 27 & 16 & 23 & 17 \\
\hline
\end{tabular}

\section{Synthesis of findings}

The research findings of six qualitative papers were included within the synthesis. A summary of the characteristics can be found in Table 2. Four of the studies were conducted in the UK, the others in Australia and the USA. A total of $51^{[3]}$ supervisor perspectives were explored. Limited information was provided regarding participant characteristics: three studies specified gender and ethnicity $(1,3,5)$, and four studies $(1,3,5,6)$ recorded the average years supervising, which ranged from 1-40 years.

\footnotetext{
${ }^{3}$ Please note, two supervisors accounts were not included in the synthesis in accordance with exclusion criteria; their occupation was not a psychologist, psychotherapist, or counsellor.
} 
Table 2.

Characteristics of Studies Included for Review

\begin{tabular}{|c|c|c|c|c|c|c|c|c|}
\hline 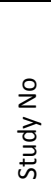 & $\begin{array}{l}\text { Author(s) } \\
\text { (year) and } \\
\text { Location }\end{array}$ & Research Aims & $\begin{array}{l}\text { Theoretical } \\
\text { Stance }\end{array}$ & $\begin{array}{l}\text { Qualitative data } \\
\text { collection method } \\
\text { (Recruitment } \\
\text { method) }\end{array}$ & $\begin{array}{l}\text { Total } \\
\text { Sample } \\
\text { (Supervisor } \\
\text { sample) }\end{array}$ & $\begin{array}{l}\text { Supervisors age, } \\
\text { gender, ethnicity, } \\
\text { and years } \\
\text { supervising }\end{array}$ & $\begin{array}{l}\text { Data analysis } \\
\text { method }\end{array}$ & $\begin{array}{l}\text { Key findings that relate to supervisors' } \\
\text { experience of supervision }\end{array}$ \\
\hline 1 & $\begin{array}{l}\text { Briggs } \\
(2010) \\
\text { UK }\end{array}$ & $\begin{array}{l}\text { To gain an understanding of } \\
\text { chartered counselling psychologist's } \\
\text { experiences } \\
\text { of supervision, particularly in relation } \\
\text { to the preparation and training that } \\
\text { they received. }\end{array}$ & $\begin{array}{l}\text { Not explicitly } \\
\text { stated }\end{array}$ & $\begin{array}{l}\text { SSI } \\
\text { (Volunteer } \\
\text { sampling: } \\
\text { graduates of } \\
\text { university) }\end{array}$ & $\begin{array}{l}6 \\
(6)\end{array}$ & $\begin{array}{l}\text { Age: 47-51 } \\
\text { Gender: } \\
\text { 5F 1M } \\
\text { Ethnicity: } \\
5 \text { White British } \\
1 \text { Asian British } \\
\text { Years Supervising: } \\
>1\end{array}$ & IPA & $\begin{array}{l}\text { There is a lack of formal training for the role of } \\
\text { supervisor. Therapists relied upon self-directed } \\
\text { learning, their previous experience and their } \\
\text { therapeutic skills to inform } \\
\text { supervisory practice. }\end{array}$ \\
\hline 2 & $\begin{array}{l}\text { Carmicha } \\
\text { el (2010) } \\
\text { UK }\end{array}$ & $\begin{array}{l}\text { To explore the diverse ways in which } \\
\text { practitioners engage in and talk about } \\
\text { supervision and ways in which they } \\
\text { draw from identified dominant } \\
\text { discourses. }\end{array}$ & Constructionist & $\begin{array}{l}\text { SSI } \\
\text { After } 12 \text { months, } \\
\text { after } 24 \text { months } \\
\text { (Volunteer } \\
\text { sampling: mental } \\
\text { health trust and } \\
\text { university) }\end{array}$ & $\begin{array}{l}9 \\
(4)^{1}\end{array}$ & $\begin{array}{l}\text { Age: NS } \\
\text { Gender: NS } \\
\text { Ethnicity: NS } \\
\text { Years Supervising: } \\
\text { NS }\end{array}$ & $\begin{array}{l}\text { Case study, } \\
\text { Foucauldian } \\
\text { discourse } \\
\text { analysis }\end{array}$ & $\begin{array}{l}\text { There is an ambiguity about the boundaries } \\
\text { and 'holding' nature of supervision. } \\
\text { Supervision is a personal experience. } \\
\text { A power imbalance in supervision remains. }\end{array}$ \\
\hline 3 & $\begin{array}{l}\text { Grant, } \\
\text { Schofield, } \\
\text { and } \\
\text { Crawford } \\
\text { (2012) } \\
\text { USA }\end{array}$ & $\begin{array}{l}\text { To examine the perspectives of highly } \\
\text { experienced supervisors regarding } \\
\text { how they manage difficulties in } \\
\text { supervision. }\end{array}$ & Constructionist & $\begin{array}{l}\text { SSI, IPR } \\
\text { (Purposive } \\
\text { sampling: via } \\
\text { authors, peer } \\
\text { identification, } \\
\text { professional } \\
\text { networks) }\end{array}$ & $\begin{array}{l}32 \\
(16)\end{array}$ & $\begin{array}{l}\text { Age: } 40 \text { 's-60's } \\
\text { Gender: } \\
\text { 5F } 11 \mathrm{M} \\
\text { Ethnicity: } \\
\text { European } \\
\text { Years Supervising: } \\
\text { 15-40 }\end{array}$ & CQR & $\begin{array}{l}\text { Major difficulties included the broad domains } \\
\text { of supervisee competence and ethical } \\
\text { behaviour, supervisee characteristics, } \\
\text { supervisor countertransference, and problems } \\
\text { in the supervisory relationship. }\end{array}$ \\
\hline 4 & $\begin{array}{l}\text { King and } \\
\text { Wheeler } \\
\text { (2000) } \\
\text { Australia }\end{array}$ & $\begin{array}{l}\text { To explore the way in which } \\
\text { experienced supervisors interpret the } \\
\text { responsibility they hold within the } \\
\text { supervisory relationship. }\end{array}$ & $\begin{array}{l}\text { Not explicitly } \\
\text { stated }\end{array}$ & $\begin{array}{l}\text { SSI } \\
\text { (Purposive } \\
\text { sampling: via } \\
\text { authors contacting } \\
\text { BAC publications) }\end{array}$ & $\begin{array}{l}10 \\
(10)\end{array}$ & $\begin{array}{l}\text { Age: NS } \\
\text { Gender: NS } \\
\text { Ethnicity: NS } \\
\text { Years Supervising: } \\
\text { NS }\end{array}$ & $\begin{array}{l}\text { Constant } \\
\text { comparative } \\
\text { method }\end{array}$ & $\begin{array}{l}\text { Supervisors did not feel they were clinically } \\
\text { responsible for their supervisee's work. There } \\
\text { was a reluctance to act against unethical } \\
\text { supervisees. Supervisors were sceptical about } \\
\text { the need for their supervisory work to be } \\
\text { supervised. }\end{array}$ \\
\hline
\end{tabular}


Supervisors' experience of delivering individual clinical supervision to qualified therapists: A meta-ethnographic synthesis

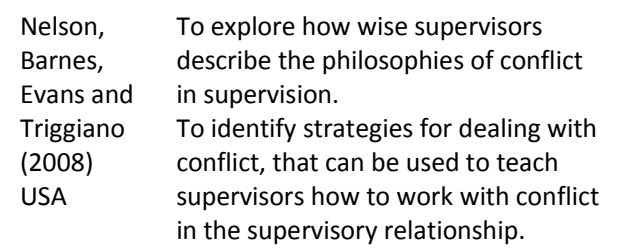

$\begin{array}{ll}\text { West and } & \text { To explore if helpful and hindering } \\ \text { Clark } & \text { events in counselling supervision } \\ \text { (2004) } & \text { would yield useful research data. To } \\ \text { UK } & \text { begin to identify the main features of }\end{array}$

UK
Not explicitly SSI

stated

sampling:
nominations
requested via
professional
listservs)

Not explicitly Interview, CPA,

IPR

(Convenience

sample)

\section{2}

$(12)^{2}$

Age: NS
Gender:
8F 4M
Ethnicity:
Caucasian
Years Supervising:
7-30

Grounded

theory, CQR

\section{Supervisors were open to conflict and} interpersonal processing, willing to

acknowledge shortcomings, developmentally

orientated, willing to learn from mistakes. They

believed in creating strong supervisory

alliances, discussing evaluation early on,

modelling openness to conflict, providing timely feedback.

\section{Age: NS}

Eender: NS

Years Supervising

Years Sup
$>20$

Supervisors and supervisees seek different

things from supervision. The supervisor's

concern is the quality of their work, a

judgement on the process of the supervision.

There is an argument for recording supervision due to imperfect recall.

BAC: British association for counselling, CPA: Comprehensive process analysis, CQR: Consensual qualitative research, IPA: Interpretative phenomenological analysis, IPR: Interpersonal process recall, NS: Not specified, SSI: Semi-structured interviews, PHA: Phenomenological heuristic analysis, F: Female, M: Male.

${ }^{1} T$ wo supervisor's accounts were not included in the synthesis, in line with the reviews exclusion criteria regarding profession.

${ }^{2} A$ supervisors account was not included in the synthesis, in line with the reviews exclusion criteria regarding profession. 
Table 3.

Cross-Comparison of Study Reports (Grouped Findings)

\begin{tabular}{|c|c|c|c|c|c|c|}
\hline \multirow[b]{2}{*}{$\begin{array}{l}\text { Third order themes } \\
\text { Subtheme }\end{array}$} & \multicolumn{6}{|c|}{$\underline{\text { Study Number }}$} \\
\hline & 1 & 2 & 3 & 4 & 5 & 6 \\
\hline \multicolumn{7}{|l|}{ Experiencing difficulties in supervision } \\
\hline Conflicting roles & $*$ & $*$ & $*$ & $*$ & $*$ & \\
\hline Power struggle & $*$ & $*$ & $*$ & $*$ & $*$ & * \\
\hline \multicolumn{7}{|l|}{ Responsibility } \\
\hline Meeting the needs of the supervisee & $*$ & $*$ & $*$ & & $*$ & \\
\hline Protecting oneself & $*$ & $*$ & & $*$ & $*$ & * \\
\hline Obligations to the service & $*$ & $*$ & $*$ & & $*$ & \\
\hline Prioritising client care & $*$ & $*$ & & $*$ & & \\
\hline \multicolumn{7}{|l|}{ Similarities to therapy } \\
\hline Parallel processes & $*$ & $*$ & $*$ & & $*$ & \\
\hline Boundaries & & $*$ & $*$ & & $*$ & \\
\hline \multicolumn{7}{|l|}{ Capabilities as a supervisor } \\
\hline Preparedness for the role & $*$ & $*$ & & & $*$ & \\
\hline Skills & $*$ & $*$ & $*$ & & $*$ & * \\
\hline Growth & $*$ & $*$ & $*$ & & $*$ & \\
\hline
\end{tabular}

Note: * Indicates the presence of articles which contributed to the third-order theme construction. 
Supervisors' experience of delivering individual clinical supervision to qualified therapists: A metaethnographic synthesis

Regarding data collection, all studies utilised interviews, and two studies incorporated interpersonal process recall $(6,3)$. The method of analysis varied.

\section{Interpretation of synthesis}

The meta-ethnography synthesis identified four third-order constructs: (1) experiencing difficulties in supervision; (2) responsibility; (3) similarities to therapy; and (4) capabilities as a supervisor. An additional eleven subthemes appeared within the overarching third-order constructs. Some refutations were apparent, which are included within the theme descriptions. All themes are presented within the crosscomparison (see Table 3) and discussed below (Phase 7).

\section{Experiencing difficulties in supervision}

'Experiencing difficulties in supervision' was identified as a recurrent theme by reciprocal translation as it was present in all studies with at least one of the subthemes: 'conflicting roles'; 'power struggle'. Participants discussed how being faced with these challenges affected their experience of supervision.

Participants within five of the studies $(1,2,3,4,5)$ expressed difficulty in managing 'conflicting roles' due to their supervisor position as a recurring theme. This was alluded to by one study (1) within their second-order construct of 'differing roles'. One participant referred to the inconsistency of being a supervisor and holding a managerial post, whereby they are required to offer support and to evaluate their supervisees: 
Supervisors' experience of delivering individual clinical supervision to qualified therapists: A metaethnographic synthesis

and the other thing I want to do, um, next time we meet, um M's asked for some sort of feedback on the client work and I'm really keen that the supervision space is confidential, but I guess we have to accept that $\mathrm{M}$ has responsibility for the organisation as well (Carmichael, 2010, p. 172).

One study (1) discussed the complexity in differentiating between the ambiguity of roles when supervising colleagues. This conflict was also apparent in relation to competing demands of supervising and a supervisor's own clinical work. For one participant, this resulted in 'resentment' towards their supervisee (Briggs, 2010, p. 266).

Both reciprocal and refutational translation identified a 'power struggle' within all the studies (1-6). Due to its nature, they felt that there was an inevitable power imbalance within supervision. Supervisors described feeling 'powerless' $(1,2,4,5,6)$ regarding the content of the discussions taking place. This appears similar to the second-order construct identified by one study (4) of 'who chooses the agenda?'. The supervisors described feeling 'vulnerable' and 'infantilised' (King \& Wheeler, 1999, p. 222). This sense of 'helplessness' (Nelson, Barnes, Evans, \& Triggiano, 2008, p. 179) is further supported by findings describing the supervisor's fear about 'what is not said?' (Carmichael, 2010, p. 189). Anxiety surrounding supervisees withholding information was discussed in four of the studies $(1,2,4,6)$, emphasising that 'supervisees were unlikely to tell the supervisor if they were knowingly behaving unethically' (4). 
Supervisors' experience of delivering individual clinical supervision to qualified therapists: A metaethnographic synthesis

Nevertheless, one study (3) disagreed with the above statements and demonstrated the power imbalance was advantageous and should be used to 'try to minimise the supervisee's tendency to idealise them' (Grant, Schofield, \& Crawford, 2012, p. 532).

Responsibility

A 'sense of responsibility' was present in all studies regarding at least one of each subtheme: 'meeting the needs of the supervisee'; 'protecting oneself'; 'obligations to the service'; 'prioritising client care'. Throughout each of the subthemes it was apparent that supervisors felt an accountability to more than one party in the responsibility associated with their role. Responsibility was identified as a secondorder construct in two of the studies $(1,4)$, which both described the 'overwhelming' and 'multi-faceted nature' of responsibility (Briggs, 2010, p. 143). A refutational translation identified feelings of responsibility towards meeting the needs of their supervisee as a third-order construct in four studies $(1,2,3,5)$. This responsibility extended to acknowledging 'the fact that we are accountable' for supervisees' work (Briggs, 2010, p.141) and feeling 'massively responsible for the quality of the intervention' (King \& Wheeler, 1999, p. 220). Studies $(2,5)$ highlighted how supervisors felt 'protective' towards supervisees. One supervisor struggled to articulate their feelings towards their supervisee:

And the word that comes to mind is the mother. I feel quite, um, um, not responsible, not protective but I feel like, Uh, .. is it respon.. I feel like they're mine. Um, they're like.. in a sense it's like they're my children and I want the best for them. (Carmichael, 2010, p. 179). 
Supervisors' experience of delivering individual clinical supervision to qualified therapists: A metaethnographic synthesis

However, some participants actively contested the idea of being accountable, stating that supervisors cannot 'accept responsibility for supervisees' (King \& Wheeler, 1999, p. 221).

Refutational translation established 'protecting oneself' as a recurrent theme in five studies $(1,2,4,5,6)$. One study (5) acknowledged the investment required to provide supervision and demonstrated that this can contribute to 'burnout' (Nelson et al., 2008, p. 178). Others $(1,2)$ recognised their individual development needs as supervisors (Carmichael, 2010, p. 164). Furthermore, there was an awareness that being responsible for a supervisee could result in action being taken against oneself. One participant conveyed this in relation to legal and financial repercussions:

the client would sue the counsellor and the counsellor would sue the supervisor. (Grant et al., 2012, p. 221).

Conversely, some supervisors rejected this belief and felt that 'I cannot be responsible for what the counsellor does' (King \& Wheeler, 1999, p. 221).

A recurrent theme amongst four studies $(1,2,3,5)$ was a responsibility towards the service. Supervisors felt a professional duty towards the organisation. Whilst supervisors respected that supervision should be confidential, they were explicit that this could be broken:

I have a responsibility to the organisation to let them know if there's something, you know, they need to know from me and the counsellor first, rather than from somewhere else. (Carmichael, 2010, p. 176-7). 
Supervisors' experience of delivering individual clinical supervision to qualified therapists: A metaethnographic synthesis

Supervisors expressed that they felt a 'pressure to produce positive outcomes' (Nelson et al., 2008, p. 179):

I think it's also a responsibility to the service to ensure that you're, the clients that are being seen by your service are being seen safely and are being offered good therapy or good psychological intervention. (Briggs, 2010, p. 144).

When supervisees were not performing appropriately and deemed to be reflecting badly upon the service, supervisors from one study (5) experienced feelings of 'anger', 'frustration', 'impatience', 'disappointment', and 'resentment'. Supervisors reported that if supervisees did not rectify this, the result could be 'termination of supervision' or if necessary, 'formal action' against a supervisee (Grant et al., 2012, p. 534).

Prioritising client care was discussed in three studies $(1,2,4)$. In one study (4), supervisors acknowledged they were 'accountable to the client for the therapeutic work both ethically and legally' (King \& Wheeler, 1999, p. 220). The dialogue provided from the supervisors demonstrated how their upmost responsibility is to 'safeguard the client' (Carmichael, 2010, p. 176).

\section{Similarities to therapy}

Many supervisors in the studies $(1,2,3,5)$ highlighted how 'in many respects some supervisory processes were similar to those that take place in therapy' (Carmichael, 2010, p. 150). A second-order construct of exploring parallel process was identified 
Supervisors' experience of delivering individual clinical supervision to qualified therapists: A metaethnographic synthesis

by one study (3), this was not defined by other studies but was explored in one study's (5) supervisor reflections of their supervisory sessions. Participants discussed how they attended to the parallel process between supervision and therapy:

I typically pay attention to the process-the interpersonal process of supervision, in addition to the content. I typically keep an eye out for parallel process themes. (Nelson et al., 2008, p. 179).

This similarity was also extended to how some participants delivered supervision, as they made 'connection between the therapeutic process and the supervisory role and likening the supervisee to the client' and used their 'personal experience and understanding of the therapeutic relationship to inform her supervisory working alliance' (Briggs, 2010, p. 125). One supervisor emphasised how her approach in supervision was identical to her therapy approach:

I dealt with it was just like I do with a therapeutic relationship. (Briggs, 2010, p. 128).

Similar to their relationships with clients, supervisors $(2,3,5)$ considered the boundaries of supervision they offered. However, their opinion of these appeared to be on a continuum. One study reported that its supervisors ensured to 'set clear boundaries' (Nelson et al., 2008, p. 177) where as another described their approach to qualified staff as 'flexible' (Carmichael, 2010, p. 144). However, supervisors (2, 3 , $4,5)$ were explicit about ensuring that supervision did not become therapy, 'all 
Supervisors' experience of delivering individual clinical supervision to qualified therapists: A metaethnographic synthesis

agreed that supervisees should have access to therapy' (King \& Wheeler, 1999, p.

223) and some supervisors felt it was their role to highlight when a supervisee had crossed this boundary and 'recommended therapy' (Nelson et al., 2008, p. 180). This 'refer to personal therapy' was identified as a second-order construct by one study (3).

\section{Capabilities as a supervisor}

All but one (4) of the studies identified 'capabilities as a supervisor' as a recurrent theme, to at least one of the subthemes 'preparedness for the role'; 'skills'; 'growth'. Refutational synthesis identified the discrepancy between feeling adequately trained to undertake the supervisor role as a recurrent theme in three studies $(1,2,5)$. These studies made clear links between feeling unprepared for the role and the absence of formal training for the position; this 'need for training' was highlighted as a second-order construct in one study (2). Some participants described their transition, from trainee to qualified role resulted in the acquisition of providing supervision within their occupational duties. This resulted feeling 'completely unprepared', reporting it was 'stressful' (Briggs, 2010, p. 117). Many of the supervisors described having nothing to guide their supervisory role on beyond their 'own experience as a supervisee' (Briggs, 2010, p. 121). The supervisors felt this bewilderment was 'avoidable' with the introduction of supervisor training:

I think there should be some more formal training before it happens I think, I don't think that you understand enough about what supervision, despite the fact that you've had supervision yourself, you don't really understand what supervision is. (Briggs, 2010, p. 130). 
Supervisors' experience of delivering individual clinical supervision to qualified therapists: A metaethnographic synthesis

In direct contrast, some participants felt that in line with their own professional development they naturally progressed from supervisee to supervisor, 'that transition I did not see as a problem' (Briggs, 2010, p. 122). They described feeling 'prepared' and defined it as blurring the lines between supervisee, supervisor' (Briggs, 2010, p. 121).

Refutational synthesis identified participant opinions about their skills as a supervisor across five studies $(1,2,3,5,6)$. Doubt in one's capabilities as a supervisor was present amongst all but one (4) of the studies. Supervisors described this as 'frightening' and likened themselves to 'the blind leading the blind' (Briggs, 2010, p. 116). They reported how they assessed 'how well they 'performed" (West \& Clark, 2004, p. 25), with concern that they left their supervisees unfulfilled, for example,

I worry that people experience me as... as a bit too fey, kind of not, a bit slippery, you know, kind of you... you... you go to him for advice and you come away and well he didn't give you much advice really. (Carmichael, 2010, p. 166).

On the opposing side, another study (5) expressed how participants felt that they were 'confident' in their skills, even when 'addressing conflictual issues with supervisees' (Nelson et al., 2008, p. 179). These supervisors described skills that enabled them to effectively deliver supervision, which included 'empathy' (2), 'openness' $(3,5)$, 'acknowledging one's own shortcomings' $(3,5)$, and 'trying to reduce shame' (3). 
Supervisors' experience of delivering individual clinical supervision to qualified therapists: A metaethnographic synthesis

A recurrent theme across studies $(1,2,3,5)$ was a sense of 'growth' as a direct consequence of being a supervisor. Participants described 'periods of intense personal and professional growth' (Nelson et al., 2008, p. 179). Supervisors illustrated how engaging in reflection after delivering supervision resulted in 'personal changes' in addition to 'changes in philosophy, role, procedures, and techniques' (Nelson et al., 2008, p. 179). This is epitomised by one supervisor describing:

monumental effects on my career and on the way I do supervision. That was the single most influential practice element in supervision in my career. (Nelson et al., 2008, p. 179). 
Supervisors' experience of delivering individual clinical supervision to qualified therapists: A metaethnographic synthesis

\section{Line of argument synthesis}

A 'line of argument synthesis' provides interpretation of a collection of ethnographies. It requires two steps, initially to compile a meta-ethnography as outlined above and secondly to make a clinical inference, providing a holistic argument (Noblit \& Hare, 1988). By synthesising the six identified papers, this review has explored supervisors' experiences of supervision. The dilemmas supervisors experienced were directly related to their conflicting responsibilities, e.g., the potential discord between protecting the client, supervisee, service, and oneself. It is neither feasible, nor realistic for supervisors to meet each one of these responsibilities and none of the studies proposed suggestions in how to manage this ambiguity. The experience of delivering supervision has significant impacts on the supervisor both personally and professionally. Providing supervision can be challenging, resulting in negative consequences for the supervisor's well-being and clinical work. It is apparent that supervisors also have developmental needs throughout their career, however these are not always addressed. The effects of administering supervision appeared dependent upon how the supervisor perceived their own supervision abilities. When therapists felt unequipped, feelings included conflict, vulnerability, and powerlessness and consequently this can generate resentment, anger, and frustration towards their supervisee. These hostile feelings may prevent quality supervision being delivered, which may generate harmful consequences for both the supervisee and client. Nevertheless, when a supervisor can empathise with their supervisee, they are able to draw upon their own experiences in supervision and apply supervisory skills more effectively. It is interpreted that if a supervisor can manage the complexities associated with the role, personal growth and development 
Supervisors' experience of delivering individual clinical supervision to qualified therapists: A metaethnographic synthesis

of skills is inevitable. A question raised, but unanswered by this review, is how a supervisor makes this transition.

\section{Discussion}

This review intended to appraise and synthesise the existing qualitative literature exploring the supervisor's experience of supervision. Four themes, with eleven subthemes, were identified that appear to influence the experience of the supervisor. A variety of potential implications for clinical practice and further research has been highlighted in this meta-ethnography.

The quality of the studies included within this review varied. Future research could be improved by authors specifying their epistemological position and the researcher's role whilst undertaking research (Paterson \& Canam, 2001). The inclusion would improve validity and enable readers to fully comprehend proposed findings. Additionally, most studies utilised convenience or volunteer sampling strategies and therefore are in jeopardy of volunteer bias and unrepresentative findings (Rosenthal, 1965). The participant characteristics provided within the studies reviewed was limited. This failure to consistently report demographic information regarding supervisees exacerbates their lack of generalisability. The absence of specification of supervisor's theoretical orientation and model of supervision has been identified in previous reviews (Kilminster \& Jolly, 2000). This information may have provided greater insight into experiences.

The identification of only six studies which explored the supervisor's perspective of delivering one-to-one supervision to qualified clinicians demonstrates the paucity of research. Consequently, this review's aims were broad to capture 
Supervisors' experience of delivering individual clinical supervision to qualified therapists: A metaethnographic synthesis

relevant papers. Without this, the review would have forfeited results such as growth discussed below. Consequently, the research aims of the studies included varied, and there was minimal reference to theory within the articles. As the literature matures, further exploration with refined aims would be beneficial to facilitate deeper understanding of particular phenomena.

This review exposed how challenging delivering supervision is, something rarely acknowledged in previous research. One reason is the multifaceted responsibilities placed upon the supervisor. The supervisors appeared to assume that the client's needs are paramount, supervisee's needs are secondary, therefore their own needs were depicted as tertiary, if considered at all. This may be a limitation of the existing research. This review highlighted that supervisors feel a sense of protection towards their supervisee, which poses questions about whether this would prevent them from raising ethical concerns. Vasquez (1992) stressed that psychotherapy supervision must develop therapists into ethically responsible clinicians. Whilst the results acknowledged that the supervisor holds some responsibility regarding the therapist's conduct, with client's welfare being paramount, it presents the ambiguity surrounding when is the right time to intervene; highlighting one of the complex dilemmas. The competing demands between supervisory and therapeutic responsibility may lead to poor decision making regarding clinical care, as increased job demands predict burnout (Xanthopoulou et al., 2007).

The experience of power struggles within supervision supports the current literature regarding hierarchical disparities and control in the supervisory pedagogy (Salvendy, 1993; Manathunga, 2007). Whilst research is emerging exploring the difficulties supervisors experience and how this can affect their confidence and self- 
Supervisors' experience of delivering individual clinical supervision to qualified therapists: A metaethnographic synthesis

efficacy (Thériault \& Gazzola, 2018), previous literature presents the supervisory dyad as a hierarchical relationship in favour of the supervisor, failing to acknowledge the finding that some supervisors can feel powerless and subjugated. The characterised roles adopted within parallel processes are power, conflict and intimacy (Grey \& Fiscalini, 1987). However, themes of intimacy were absent in both third and second-order constructs. Supervisees' experiences of conflict in supervision have been well researched, highlighting power struggles, feelings of anger and anxiety (Magnuson, Wilcoxon, \& Norem, 2000; Martinez, Davis, \& Dahl, 2000; Nelson \& Friedlander, 2001). These research findings mirror the themes identified within this review and could provide support for the bi-directionality of parallel process. Negative feelings towards supervisees may prevent supervisors from providing quality supervision. Watkins (1997) found that ineffective supervision contributed to supervisee deterioration, having parallel ramifications for clients (Mays \& Frank, 1985), and consequently violates ethical obligations (BPS, 2017). Therefore, caution should be taken to ensure that adverse feelings towards supervisees do not progress into harmful supervision. Ellis (2001) proposed that constructs such as those found in this review (limited supervisor training; power struggles) contributed to harmful or bad supervision. Hence, it is essential that supervisors receive the necessary support to prevent this.

Mental health services have acknowledged the importance of providing extensive supervisory training (Borders \& Brown, 2005), found to foster supervisor identity, a core competency of psychologists (American Psychological Association, 2012). However, some participants within the review highlighted a gap in their theoretical knowledge and lack of formal training (Briggs, 2010). It is worth noting that counselling psychologists identified this, who, in contrast to clinical 
Supervisors' experience of delivering individual clinical supervision to qualified therapists: A metaethnographic synthesis

psychologists, are not required to undertake supervisor training. This contradicts previous research which identified that counselling programmes deliver more rigorous supervision training when compared to clinical psychology (Scott, Ingram, Vitanza, \& Smith 2000). Milne and Watkins (2014) emphasised that supervisors should also be competent, capable, and ethical, questioning whether the appropriate support agencies are accessible to supervisors. Bos, Löfmark, and Törnkvist (2009) emphasised supervisors need to receive support from clinical managers, comparing this to universities assistance when supervising students. Ladany, Constantine, Miller, Erickson, and Muse-Burke's (2000) found that supervisors had received limited training regarding managing countertransference. Supervisors are expected to model appropriate and ethical behaviour. However, with inadequate skills to manage personal reactions, countertransference and parallel process, this may have implications on supervision outcome and participants' development (Ladany et al., 2000). Additional exploration regarding disparity of experiences may provide clarity for the professions training practices.

The review highlighted that delivering supervision facilitates improvement of professional skills and growth. Whilst growth was only reflected in a few studies, it is worth acknowledging the poignancy of this development, leading to profound personal changes. These findings complement research on supervisee's perspectives, whom stated that supervision had positive impacts upon self-efficacy and development (Wheeler \& Richards, 2007). Additional research enquiring how this development occurs would be beneficial.

This review is not without limitations. The studies within this review were based in various countries and different healthcare systems may have influenced supervisors' experiences. Hawkins and Shohet (2006) described significant 
Supervisors' experience of delivering individual clinical supervision to qualified therapists: A metaethnographic synthesis

differences in therapy application between the UK and USA, which may mirror supervision practices. Therefore, variance across cultures should be considered when interpreting results.

Some may perceive the absence of quantitative studies from this review a limitation, as the combination of both quantitative and qualitative approaches has been viewed favourably when influencing policy (Dixon-Woods, Agarwal, Jones, Young, \& Sutton, 2005). However, the aim of this review was to synthesise research exploring how supervisors experience supervision, which would be absent in quantitative literature. The inclusion of diverse methodologies has been highlighted to limit compatibility when used in conjunction in meta-synthesis (Zimmer, 2006).

Furthermore, the inclusion of grey literature may have reduced the quality of the review, as articles have not undergone peer-review. Whilst peer-review publications have been viewed as an assurance for research quality (Grayson, 2002), some have argued they falsify the literature by only including positive outcomes (Asthana \& Halliday, 2006). McAuley, Tugwell, and Moher (2000) emphasised the need to include grey literature in meta-analyses to prevent exaggerated conclusions being drawn from unrepresentative findings.

A critical interpretive approach was utilised in this review and therefore considerations should be made about the generalisability of the above findings. As aforementioned, researcher bias was considered during the compilation of this review to minimise its effects (Malim, 2001). A reflective journal enabled the comparison of research assumptions with the meta-ethnography results. Whilst there were some similarities, such as anticipated responsibility, new themes also emerged demonstrating receptiveness. Upon the identification of new themes, alternative resources and perspectives were considered to facilitate triangulation (Patton, 1999). 
Supervisors' experience of delivering individual clinical supervision to qualified therapists: A metaethnographic synthesis

Nevertheless, the first author acknowledged that their educational and professional background will have contributed to the translation of themes, and also the understanding which precedes the conclusions made (Koch \& Harrington, 1998). Therefore, the first author acknowledges that the themes presented are her interpretation, however, attempts have been outlined to present transparency in their attainment.

In conclusion, this synthesis emphasises different supervisor experiences associated with supervision, including conflicting roles, responsibilities, and similarities to therapy. If managed effectively, supervising has the potential to increase skillsets and can result in personal and professional growth, but this is not a unanimous result. Other outcomes include resentment towards supervisees, unmet supervisor needs, and burnout. Further exploration into supervisors' experiences, with an emphasis on how they manage the multitude of responsibilities within the role would be advantageous. This in turn should lead to more balanced occupational duties, which may prevent negative consequences. However, this would need to be explored further by future research. 
Supervisors' experience of delivering individual clinical supervision to qualified therapists: A metaethnographic synthesis

\section{References}

Adams, T., Holman, M., \& Mitchell, G. (2003), "Multi-disciplinary teamworking”, in Keady, J., Clarke, C., \& Adams, T (Eds.), Community mental health nursing and dementia care: practice perspectives, McGraw-Hill Education, UK, pp. 3344.

American Psychological Association. (2012), "Benchmarks clusters and core competencies", available at: http://www.apa.org/ed/graduate/benchmarksclusters-competencies.pdf (accessed 21 October 2017).

Aryee, S., Sun, L. Y., Chen, Z. X. G., \& Debrah, Y. A. (2008), "Abusive supervision and contextual performance: The mediating role of emotional exhaustion and the moderating role of work unit structure", Management and Organization Review, Vol. 4 No. 3, pp. 393-411. doi: 10.1111/j.1740-8784.2008.00118.x

Asthana, S., \& Halliday, J. (2006), “Developing an evidence base for policies and interventions to address health inequalities: The analysis of "public health regimes"”, The Milbank Quarterly, Vol. 84 No. 3, pp. 577-603. doi:

10.1111/j.1468-0009.2006.00459.x

Atkins, S., Lewin, S., Smith, H., Engel, M., Fretheim, A., \& Volmink, J. (2008), "Conducting a meta-ethnography of qualitative literature: Lessons learnt", BMC Medical Research Methodology, Vol. 8 No. 1, pp. 21. doi: 10.1186/14712288-8-21

Austin, Z., \& Sutton, J. (2014), "Qualitative research: Getting started", The Canadian Journal of Hospital Pharmacy, Vol. 67 No. 6, pp. 436-440. doi: 10.4212/cjhp.v67i6.1406

Bernard, J., \& Goodyear, R. (2009), Fundamentals of clinical supervision: Fourth Edition, Pearson Education, Boston. 
Supervisors' experience of delivering individual clinical supervision to qualified therapists: A metaethnographic synthesis

Binder, J. L., \& Strupp, H. H. (1997), “Supervision of psychodynamic therapies”, in Watkins, C. E. Jr., (Ed.), Handbook of psychotherapy supervision, Wiley, New York, pp. 44-62.

Borders, L. D. (2014), "Best practices in clinical supervision: Another step in delineating effective supervision practice", American Journal of Psychotherapy, Vol. 68 No. 2, pp. 151-162. doi:

10.1176/appi.psychotherapy.2014.68.2.151

Borders, L. D., \& Brown, L. L. (2005), The new handbook of counseling supervision, Lahaska/Lawrence Erlbaum, Mahwah, New Jersey.

Bos, E., Löfmark, A., \& Törnkvist, L. (2009), "District nurses' experience of supervising nursing students in primary health care: A pre-and postimplementation questionnaire study", Nurse education in practice, Vol. 9 No. 6, pp.361-366. doi: 10.1016/j.nepr.2008.10.007

Bradshaw, T., Butterworth, A., \& Mairs, H. (2007), "Does structured clinical supervision during psychosocial intervention education enhance outcome for mental health nurses and the service users they work with?", Journal of Psychiatric and Mental Health Nursing, Vol. 14, pp. 4-12. doi: 10.1111/j.13652850.2007.01021.x

Briggs, D. (2010), A Qualitative Study Using Interpretative Phenomenological Analysis to Explore Chartered Counselling Psychologists Experience of Supervision (Unpublished doctoral thesis), Wolverhampton, University of Wolverhampton.

British Association for Counselling and Psychotherapy. (2010), BACP: Supervision, BACP, Lutterworth. 
Supervisors' experience of delivering individual clinical supervision to qualified therapists: A metaethnographic synthesis

British Psychological Society (2007), "Criteria for the accrediting of post-graduate training programmes in clinical psychology", Division of Clinical Psychology, Committee for Training in Clinical Psychology, BPS, Leicester.

British Psychological Society. (2014), DCP policy on supervision, BPS, Leicester.

British Psychological Society. (2017), Practice Guidelines. Third Edition, BPS, Leicester.

Britten, N., Campbell, R., Pope, C., Donovan, J., Morgan, M., \& Pill, R. (2002), "Using meta ethnography to synthesise qualitative research: A worked example", Journal of Health Services Research \& Policy, Vol. 7 No. 4, pp. 209-215. doi: 10.1258/135581902320432732

Campbell, R., Pound, P., Morgan, M., Daker-White, G., Britten, N., Pill, R., ... \& Donovan, J. (2012), "Evaluating meta ethnography: systematic analysis and synthesis of qualitative research", Health Technology Assessment, Vol. 15 No. 43. doi: $10.3310 /$ hta15430

Campbell, R., Pound, P., Pope, C., Britten, N., Pill, R., Morgan, M., \& Donovan, J. (2003), "Evaluating meta-ethnography: A synthesis of qualitative research on lay experiences of diabetes and diabetes care", Social Science \& Medicine, Vol. 56 Vol. 4, pp. 671-684. doi: 10.1016/S0277-9536(02)00064-3

Carmichael, H. (2010), Clinical supervision in mental health: A Foucauldian discourse analysis (Unpublished doctoral thesis), Southampton, University of Southampton Solent.

Carroll, M. (1996), Counselling supervision: Theory, skills and practice, Cassell, London. 
Supervisors' experience of delivering individual clinical supervision to qualified therapists: A metaethnographic synthesis

Critical appraisal skills programme. (2017), “CASP Systematic Review Checklist: 10 questions to help you make sense of qualitative research", available at: http://www.casp-uk.net/casp-tools-checklists (accessed 21 October 2017).

Dixon-Woods, M., Agarwal, S., Jones, D., Young, B., \& Sutton, A. (2005), "Synthesising qualitative and quantitative evidence: a review of possible methods", Journal of health services research \& policy, Vol. 10 No. 1, pp. 4553.

Dixon-Woods, M., Shaw, R. L., Agarwal, S., \& Smith, J. A. (2004), "The problem of appraising qualitative research", Quality \& Safety in Health Care, Vol. 13 No. 3, pp. 223-225.

Ducat, W. (2013), "What do we really know about best practice allied health professional supervision? the challenges and rewards of preparing a systematic review and preliminary findings", paper presented at the $12^{\text {th }}$ National rural health conference, 7-10 April 2013, Adelaide Convention Centre, Australia, available at:

https://www.researchgate.net/profile/Wendy Ducat/publication/279456109 W hat do we really know about best practice allied health professional sup ervision The challenges and rewards of preparing a systematic review a nd preliminary findings/links/55936e8108ae5af2b0eb7df0/What-do-wereally-know-about-best-practice-allied-health-professional-supervision-Thechallenges-and-rewards-of-preparing-a-systematic-review-and-preliminaryfindings.pdf (accessed 21 October 2017).

Ducat, W. H., \& Kumar, S. (2015), "A systematic review of professional supervision experiences and effects for allied health practitioners working in non- 
Supervisors' experience of delivering individual clinical supervision to qualified therapists: A metaethnographic synthesis

metropolitan health care settings", Journal of Multidisciplinary Healthcare, Vol. 8, pp. 397-407. doi: 10.2147/JMDH.S84557

Ellis, M. V. (2001), "Harmful supervision, a cause for alarm: Comment on Gray et al. (2001) and Nelson and Friedlander (2001)", Journal of Counseling Psychology, Vol. 48 No. 4, pp. 401-406. doi: 10.1037/0022-0167.48.4.401

Ekstein, R., \& Wallerstein, R. S. (1958), The teaching and learning of psychotherapy, Basic Books, New York.

Evans, D., \& Pearson, A. (2001), "Systematic reviews: Gatekeepers of nursing knowledge", Journal of Clinical Nursing, Vol. 10 No. 5, pp. 593-599. doi: 10.1046/j.1365-2702.2001.00517.x

Finfgeld, D. L. (2003), "Metasynthesis: The state of the art-so far", Qualitative Health Research, Vol. 13 No. 7, pp. 893-904. doi:

$10.1177 / 1049732303253462$

Freitas, G. J. (2002), "The impact of psychotherapy supervision on client outcome: A critical examination of 2 decades of research", Psychotherapy: Theory, Research, Practice, Training, Vol. 39 No. 4, pp. 354. doi: 10.1037/00333204.39.4.354

Fleming, I., \& Steen, L. (2013), Supervision and clinical psychology: Theory, practice and perspectives, Routledge, UK.

Garside, R. (2014), "Should we appraise the quality of qualitative research reports for systematic reviews, and if so, how?", Innovation: The European Journal of Social Science Research, Vol. 27 No. 1, pp. 67-79. doi:

$10.1080 / 13511610.2013 .777270$ 
Supervisors' experience of delivering individual clinical supervision to qualified therapists: A metaethnographic synthesis

Gautier, D. (2009), "The impact of sibling rivalry in group supervision", The Journal of the British Association for Psychoanalytic \& Psychodynamic Supervision, Vol. 1, pp. 6-8.

Grant, J., Schofield, M. J., \& Crawford, S. (2012), "Managing difficulties in supervision: Supervisors' perspectives", Journal of counseling psychology, Vol. 59 No. 4, pp. 528. doi: 10.1037/a0030000

Grayson, L. (2002), "Evidence based policy and the quality of evidence: Rethinking peer review", ESRC UK Centre for Evidence Based Policy and Practice, UK. Green, D., \& Youngson, S. (2003), "Discussion paper regarding DCP policy on continued supervision", Division of Clinical Psychology, British Psychological Society, Leicester.

Grey, A. L., \& Fiscalini, J. (1987), "Parallel process as transferencecountertransference interaction", Psychoanalytic Psychology, Vol. 4 No. 2, pp. 131. doi: $10.1037 / \mathrm{h} 0079131$

Hawkins, P., \& Shohet, R. (2006), Supervision in the helping professions, McGrawHill Education: UK.

Inman, A. G., Hutman, H., Pendse, A., Devdas, L., Luu, L., \& Ellis, M. V. (2014), "Current Trends Concerning Supervisors, Supervisees, and Clients in Clinical Supervision”"', in Watkins Jr, C. E., \& Milne, D. L. (Eds.), The Wiley international handbook of clinical supervision, John Wiley \& Sons, UK, pp. 61102

Jacobsen, C. H. (2007), "A qualitative single case study of parallel processes", Counselling and Psychotherapy Research, Vol. 7, pp. 26-33. doi: $10.1080 / 14733140601140410$ 
Supervisors' experience of delivering individual clinical supervision to qualified therapists: A metaethnographic synthesis

Kilminster, S. M., \& Jolly, B. C. (2000), "Effective supervision in clinical practice settings. a literature review", Medical Education, Vol. 34 No. 10, pp. 827-840. doi: 10.1046/j.1365-2923.2000.00758.x

King, D., \& Wheeler, S. (1999), "The responsibilities of counsellor supervisors: A qualitative study", British Journal of Guidance and Counselling, Vol. 27 No. 2, pp. 215-229. doi: 10.1080/03069889908256266

Koch, T., \& Harrington, A. (1998), "Reconceptualizing rigour: the case for reflexivity", Journal of advanced nursing, Vol. 28 No. 4, pp. 882-890. doi: 10.1046/j.13652648.1998.00725.x

Koltz, R. L., Odegard, M. A., Feit, S. S., Provost, K., \& Smith, T. (2012), "Parallel process and isomorphism: A model for decision making in the supervisory triad", The Family Journal, Vol. 20 No. 3, pp. 233-238. doi:

$10.1177 / 1066480712448788$

Ladany, N., Constantine, M. G., Miller, K., Erickson, C. D., \& Muse-Burke, J. L. (2000), "Supervisor countertransference: A qualitative investigation into its identification and description", Journal of Counseling Psychology, Vol. 47, pp. $102-115$.

Lambert, M. J., \& Barley, D. E. (2001), "Research summary on the therapeutic relationship and psychotherapy outcome", Psychotherapy: Theory, research, practice, training, Vol. 38 No. 4, pp. 357. doi: 10.1037/0033-3204.38.4.357

Liberati, A., Altman, D. G., Tetzlaff, J., Mulrow, C., Gøtzsche, P. C., loannidis, J. P., . . . Moher, D. (2009), "The PRISMA statement for reporting systematic reviews and meta-analyses of studies that evaluate health care interventions:

Explanation and elaboration", PLoS Medicine, Vol. 6 No. 7. doi:

10.1371/journal.pmed. 1000100 
Supervisors' experience of delivering individual clinical supervision to qualified therapists: A metaethnographic synthesis

Lichtenberg, J. W. (2007), "What makes for effective supervision? In search of clinical outcomes", Professional Psychology: Research and Practice, Vol. 38, pp. 27-28. doi: 10.1037/0735-7028.38.3.268

Magnuson, S., Wilcoxon, S. A., \& Norem, K. (2000), "A profile of lousy supervision: Experienced counselors' perspectives", Counselor Education and Supervision, Vol. 39, pp. 189-202. doi: 10.1002/j.1556-6978.2000.tb01231.x Malim, T. (2001), “Dealing With Biases in Qualitative Research: A Balancing Act for Researchers", poster presented at Qualitative Research convention 2001: Navigating Challenges, 25-26 October 2001, Malaya: Kuala Lumpur, available at: http://merr.utm.my/4087/ (accessed 21 October 2017).

Manathunga, C. (2007), "Supervision as mentoring: The role of power and boundary crossing", Studies in Continuing education, Vol. 29 No. 2, pp. 207-221. doi: $10.1080 / 01580370701424650$

Martinez, L. J., Davis, K. C., \& Dahl, B. (2000), "Feminist ethical challenges in supervision", Women \& Therapy, Vol. 22, pp. 35-54. doi: 10.1300/J015v22n04_03

Mays, D. T., \& Franks, C. M. (1985), Negative outcome in psychotherapy and what to do about it, Springer, New York.

McAuley, L., Tugwell, P., \& Moher, D. (2000), "Does the inclusion of grey literature influence estimates of intervention effectiveness reported in meta-analyses?", The Lancet, Vol. 356 No. 9237, pp. 1228-1231.

Miller, W. R. (2010), "Qualitative research findings as evidence: Utility in nursing practice. Clinical Nurse Specialist (CNS)", Vol. 24 No. 4, pp. 191-193. doi: 10.1097/NUR.0b013e3181e36087 
Supervisors' experience of delivering individual clinical supervision to qualified therapists: A metaethnographic synthesis

Milne, D. (2007). An empirical definition of clinical supervision. British Journal of Clinical Psychology, 46(4), 437-447.

Milne, D., Reiser, R., Aylott, H., Dunkerley, C., Fitzpatrick, H., \& Wharton, S. (2010), "The systematic review as an empirical approach to improving CBT supervision", International Journal of Cognitive Therapy, Vol. 3 No. 3, pp. 278294. doi: $10.1521 /$ ijct.2010.3.3.278

Milne, D. L., \& Watkins Jr, C. E. (2014), "Defining and Understanding Clinical Supervision A Functional Approach", in Watkins Jr, C. E., \& Milne, D. L. (Eds.), The Wiley international handbook of clinical supervision, John Wiley \& Sons, UK, pp. 7-8.

Moher, D., Shamseer, L., Clarke, M., Ghersi, D., Liberati, A., Petticrew, M., . . . Stewart, L. A. (2015), "Preferred reporting items for systematic review and meta-analysis protocols (PRISMA-P) 2015 statement", Systematic Reviews, Vol. 4 No. 1, pp. 1. doi: 10.1186/2046-4053-4-1

Morrissey, J., \& Tribe, R. (2001), "Parallel process in supervision”, Counselling Psychology Quarterly, Vol. 14, pp. 103-110. doi: 10.1080/09515070126329

Nelson, M. L., Barnes, K. L., Evans, A. L., \& Triggiano, P. J. (2008), "Working with conflict in clinical supervision: Wise supervisors' perspectives", Journal of Counseling Psychology, Vol. 55 No. 2, pp. 172. doi: 10.1037/00220167.55.2.172

Nelson, M. L., \& Friedlander, M. L. (2001), "A close look at conflictual supervisory relationships: The trainee's perspective", Journal of Counseling Psychology, Vol. 48 No. 4, pp. 384. doi: 10.1037/0022-0167.48.4.384

Noblit, G. W., \& Hare, R. D. (1988), Meta-ethnography: Synthesizing qualitative studies, Sage, New York. 
Supervisors' experience of delivering individual clinical supervision to qualified therapists: A metaethnographic synthesis

Ögren, M-L., Boëthius, S. B., \& Sundin, E. (2014), "Challenges and Possibilities in Group Supervision", in Watkins Jr, C. E., \& Milne, D. L. (Eds.), The Wiley international handbook of clinical supervision, John Wiley \& Sons, UK, pp. 648-669.

Ögren, M. L., \& Jonsson, C. O. (2004), "Psychotherapeutic skill following group supervision according to supervisees and supervisors", The Clinical Supervisor, Vol. 22 No. 1, pp. 35-58. doi: 10.13000/j001v22n0104

Pannucci, C. J., \& Wilkins, E. G. (2010), "Identifying and avoiding bias in research", Plastic and reconstructive surgery, Vol. 126 No. 2, pp. 619. doi: 10.1097/PRS.0b013e3181de24bc

Paterson, B. L., \& Canam, C. (2001), Meta-study of qualitative health research: A practical guide to meta-analysis and meta-synthesis, Sage, New York.

Patton, M. Q. (1999), "Enhancing the quality and credibility of qualitative analysis", Health services research, Vol. 34 No. 5 Pt 2, pp. 1189.

Pearson, Q. M. (2000), “Opportunities and challenges in the supervisory relationship: Implications for counselor supervision", Journal of Mental Health Counseling, Vol. 22 No. 4, pp. 283.

Raichelson, S. H., Herron, W. G., Primavera, L. H., \& Ramirez, S. M. (1997), "Incidence and effects of parallel process in psychotherapy supervision", The Clinical Supervisor, Vol. 15 No. 2, pp. 37-48. doi: 10.1300/J001v15n02_03 Ramos-Sánchez, L., Esnil, E., Goodwin, A., Riggs, S., Touster, L. O., Wright, L. K., ... \& Rodolfa, E. (2002), "Negative supervisory events: Effects on supervision and supervisory alliance", Professional Psychology: Research and Practice, Vol. 33 No. 2, pp. 197. doi: 10.1037/0735-7028.33.2.197

Richards, L. (2014), Handling qualitative data: A practical guide, Sage, New York. 
Supervisors' experience of delivering individual clinical supervision to qualified therapists: A metaethnographic synthesis

Rosenthal, R. (1965), "The volunteer subject”, Human Relations, Vol. 18 No. 4, pp. 389-406. doi: 10.1177/001872676501800407

Rubinstein, G. (1993), "Supervision and psychotherapy: Toward redefining the differences", The Clinical Supervisor, Vol. 10 No. 2, pp. 97-116. doi: 10.1300/J001v10n02_07

Salvendy, J. T. (1993), "Control and power in supervision", International Journal of Group Psychotherapy, Vol. 43 No. 3, pp. 363-376. doi:

10.1080/00207284.1993.11732599

Sandelowski, M., Docherty, S., \& Emden, C. (1997), "Focus on qualitative methods qualitative metasynthesis: Issues and techniques", Research in Nursing and Health, Vol. 20, pp. 365-372.

Schutz, A. (1962), “Collected papers: Vol. 1: The problem of social reality”, Martinus Nijhoff, Netherlands.

Scott, K. J., Ingram, K. M., Vitanza, S. A., \& Smith, N. G. (2000), “Training in supervision: A survey of current practices", The Counseling Psychologist, Vol. 28, pp. 403-422. doi: 10.1177/0011000000283007

Searles, H. F. (1955), "The informational value of the supervisor's emotional experiences", Psychiatry, Vol. 18 No. 2, pp. 135-146. doi: $10.1080 / 00332747.1955 .11023001$

Seligman, M. E., \& Csikszentmihalyi, M. (2014), "Positive psychology: An introduction", in M. Csikszentmihalyi (Ed.), Flow and the foundations of positive psychology, Springer, Netherlands, pp. 279-298.

Suri, H. (2011), "Purposeful sampling in qualitative research synthesis", Qualitative Research Journal, Vol. 11 No. 2, pp. 63-75. doi: 10.3316/QRJ1102063 
Supervisors' experience of delivering individual clinical supervision to qualified therapists: A metaethnographic synthesis

Thériault, A., \& Gazzola, N. (2018). Dilemmas that undermine supervisor confidence. Counselling and Psychotherapy Research, 18(1), 14-25.

Thomas, J., \& Harden, A. (2008), "Methods for the thematic synthesis of qualitative research in systematic reviews", BMC Medical Research Methodology, Vol. 8 No. 1, pp. 45. doi: 10.1186/1471-2288-8-45

Thorne, S. (2016), Interpretive description: Qualitative research for applied practice, Routledge, UK.

Trede, F., McEwen, C., Kenny, A., \& O'Meara, P. (2014), "Supervisors' experiences of workplace supervision of nursing and paramedic students in rural settings: a scoping review", Nurse education today, Vol. 34 No. 5, pp. 783-788. doi: 10.1016/j.nedt.2013.10.003

Vallance, K. (2005), "Exploring counsellor perceptions of the impact of counselling supervision on clients", Counselling and Psychotherapy Research, Vol. 5 No. 2, pp. 107-110. doi: $10.1080 / 03069880412331303330$

Vasquez, M. J. (1992), "Psychologist as clinical supervisor: Promoting ethical practice", Professional Psychology: Research and Practice, Vol. 23 No. 3, pp. 196. doi: $10.1037 / 0735-7028.23 .3 .196$

Walsh, D., \& Downe, S. (2005), "Meta-synthesis method for qualitative research: A literature review", Journal of Advanced Nursing, Vol. 50 No. 2, pp. 204-211. doi: 10.1111/j.1365-2648.2005.03380.x

Watkins Jr, C. E. (1997), "The ineffective psychotherapy supervisor: Some reflections about bad behaviors, poor process, and offensive outcomes", The Clinical Supervisor, Vol. 16 No. 1, pp. 163-180. doi: 10.1300/J001v16n01_09 
Supervisors' experience of delivering individual clinical supervision to qualified therapists: A metaethnographic synthesis

Watkins Jr, C. E. (2011), "Does psychotherapy supervision contribute to patient outcomes? Considering thirty years of research", The Clinical Supervisor, Vol. 30 No. 2, pp. 235-256. doi: 10.1080/07325223.2011.619417

Watkins Jr, C. E. (2017), "Reconsidering parallel process in psychotherapy supervision: On parsimony, rival hypotheses, and alternate explanations", Psychoanalytic Psychology, Vol. 34 No. 4, pp. 506-515. doi: 10.1037/pap0000127

West, W., \& Clark, V. (2004), "Learnings from a qualitative study into counselling supervision: Listening to supervisor and supervisee", Counselling and Psychotherapy Research, Vol. 4 No. 2, pp. 20-26. doi: $10.1080 / 14733140412331383903$

Wheeler, S. (2007), "What shall we do with the wounded healer? The supervisor's dilemma", Psychodynamic practice, Vol. 13 No. 3, pp. 245-256. doi: $10.1080 / 14753630701455838$

Wheeler, S., \& Richards, K. (2007), "The impact of clinical supervision on counsellors and therapists, their practice and their clients. A systematic review of the literature", Counselling and Psychotherapy Research, Vol. 7 No. 1, pp. 54-65. doi: 10.1080/14733140601185274

Worthington, E. L. (1987), "Changes in supervision as counselors and supervisors gain experience: A review", Professional Psychology: Research and Practice, Vol. 18 No. 3, pp. 189. doi: 10.1037/1931-3918.S.2.133

Xanthopoulou, D., Bakker, A. B., Dollard, M. F., Demerouti, E., Schaufeli, W. B., Taris, T. W., \& Schreurs, P. J. (2007), "When do job demands particularly predict burnout? The moderating role of job resources", Journal of managerial psychology, Vol. 22 No. 8, pp. 766-786. doi: 10.1108/02683940710837714 
Supervisors' experience of delivering individual clinical supervision to qualified therapists: A metaethnographic synthesis

Zimmer, L. (2006), “Qualitative meta-synthesis: A question of dialoguing with texts", Journal of Advanced Nursing, Vol. 53 No. 3, pp. 311-318. doi:

10.1111/j.1365-2648.2006.03721.x 